\begin{tabular}{c|c|c}
\hline \hline $\begin{array}{c}\text { Vol. 591: 1, 2018 } \\
\text { https://doi.org/10.3354/meps12413 }\end{array}$ & $\begin{array}{c}\text { MARINE ECOLOGY PROGRESS SERIES } \\
\text { Mar Ecol Prog Ser }\end{array}$ & Published March 19 \\
\hline
\end{tabular}

\title{
In Memoriam Mary Needler Arai
}

Mary Elizabeth Needler Arai (1932-2017) passed away at her home in Nanaimo, BC (Canada). A world renowned zoologist and third-generation female marine biologist, Mary dedicated her life to science and to her family.

Mary obtained a BSc (Honours) in Biology from the University of New Brunswick in 1952, an MA in Zoology from the University of Toronto in 1956 (working partly in Toronto and partly in England at University College London and the Plymouth Marine Laboratory), and a PhD from the University of California, Los Angeles, in 1960. Her dissertation described 'The taxonomy, morphology and neuromuscular physiology of Ceriantharia'. While at the University of California, she married Hisao Arai, a fellow doctoral student working on fish parasitology.

Mary and Hisao worked at several institutions in the United States and Canada before Hisao was hired as an Assistant Professor and Mary as a Sessional Instructor in Biological Sciences at the University of Calgary in 1963. Mary advanced to Assistant Professor in 1969 because of her highquality research and the positive impact of her teaching, particularly on female undergraduates. Throughout her career, Mary has been a role model for women in science due to her exceptional scholarship, kindness, integrity, intelligence, and class.

Because of her training in invertebrate neuromuscular physiology, Mary initially taught a wide variety of courses in physiology. Later in her career, her interests shifted to cnidarian behavioral ecology, and her teaching assignments changed to classes on invertebrates and cnidarian biology. Her publications also transitioned from reports on physiological experiments to scholarly systematic and biological monographs on cnidarians. In 1997, Mary published the exceptionally important book 'A functional biology of Scyphozoa' that effectively defined a new discipline in ocean sciences focused on gelatinous zooplankton.

The jellyfish community benefited greatly from Mary's scientific work. Some of the papers she published on jellyfish between 1973 and 2009 focused on topics that only caught on within the wider research community decades later; other studies remain unique to this day, such as her works on chemical stimulation of jellyfish feeding by prey and on digestion of jellyfish by fish. The variety of jellyfish in northern Puget

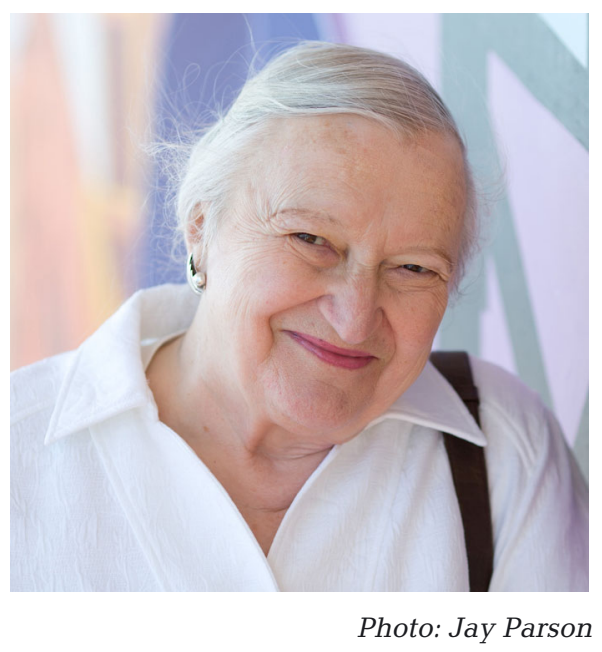

Sound inspired many researchers with similar interests and attracted them to this specific region. Mary promoted understanding of the interactions between jellyfish and fish. Her contributions to knowledge about jellyfish were honored in 2013 with a Lifetime Achievement Award at The International Jellyfish Bloom Symposium. Her accomplishments also include an honorary lifetime membership to the Canadian Society of Zoologists and an Honorary Doctorate of Science from the University of New Brunswick (Saint John, Canada).

Mary and Hisao retired in 1996 and moved to the home they built (including a laboratory and library) next to the Pacific Biological Station in Nanaimo, where Mary and Hisao both had Adjunct Emeritus appointments. Mary's life came to an end fittingly close to the sea where many of her studies had been conducted, and her ashes were returned to these waters by her family - a poignant tribute to a strong, independent scientist. She will be greatly missed by her many colleagues and students, whom she helped and inspired.

Jennifer E. Purcell

Department of Biology, Western Washington University, Bellingham, WA 98225, USA

William M. Hamner, Professor Emeritus

Department of Ecology \& Evolutionary Biology University of California, Los Angeles, CA 90095, USA

David W. Welch

Kintama, BC V9S 3B3, Canada 